\title{
The relationship among diet, alimentary tract morphology, and life history for five species of rodents from the central Argentine pampa
}

\author{
Barbara A. ELLIS, James N. MILLS, Eduardo J. T. KENNEDY, \\ Julio I. MAIZTEGUI, and James E. CHILDS
}

Ellis B. A., Mills J. N., Kennedy E. J. T., Maiztegui J. I., and Childs J. E. 1994. The relationship among diet, alimentary tract morphology, and life history for five species of rodents from the central Argentine pampa. Acta theriol. 39: 345-355.

A suite of characters describing digestive tract structure has been hypothesized to reflect the relative degree of specialization of the digestive system of rodent species along a continuum from a proteinaceous diet of seeds and insects to a cellulosic diet of vegetation. Similarly, it has been proposed that life history traits might reflect diet and digestive tract structure, with the most opportunistic species consuming the most energy-rich diets of seeds and insects. The five members of the rodent assemblage of agroecosystems of the Argentine pampa were found to be omnivores and varied in the relative proportions of seeds, insects, and vegetation consumed. On a gross level, diet reflected life history; the most opportunistic species (smallest body size, highest fecundity, preference for disturbed habitats) consumed the most energy-rich diet, while the least opportunistic species consumed the most vegetation. However, comparative digestive tract structure was generally converse to that predicted, based on diet. Failure to observe predicted correlations may be due in part to seasonal variability in diet, lack of evolutionary relevance of crop habitats, or flaws in the underlying hypotheses. Alternatively, the observed variation in digestive tract structure may reflect the spectrum of variation encountered within an omnivore rodent guild rather than the degree of food specialization.

Department of Immunology and Infectious Diseases, School of Hygiene and Public Health, Johns Hopkins University, 615 N. Wolfe St., Baltimore, MD 21205 U.S.A. (BAE); Centers for Disease Control and Prevention, Viral and Rickettsial Zoonoses Branch, 1600 Clifton, Atlanta, GA 30333 U.S.A. (JNM, JEC); Instituto Nacional de Enfermedades Virales Humanas, C. C. 195, 2700 Pergamino (Buenos Aires), Argentina (EJTK, JIM)

Key words: Calomys laucha, Calomys musculinus, Akodon azarae, Bolomys obscurus, Oligoryzomys flavescens, diet, digestive tract, Argentina

\section{Introduction}

Differences in feeding habits among mammals are often reflected in the structure of their alimentary tracts. Even within families, where genera with different food habits do not display structural differences of the digestive tract, the influence of food habits is often evident in the relative lengths of the different 
sections of the intestine (Davis and Golley 1963). Vorontsov (1962) has related observed differences in digestive tract morphology to evolutionary adaptations for an herbivorous diet. The transition from a high-energy, high-protein-lipid diet of seeds and small invertebrates, to a low-energy, high-cellulose diet of vegetative parts of plants was hypothesized to have resulted in several evolutionary modifications in the digestive tracts of muroid rodents (Vorontsov 1962). These would include: increased relative size of the total digestive tract, decreased relative size of the small intestine, increased relative size and complexity of the cecum, decreased relative surface area of the stomach covered by glandular epithelium in favor of cornified epithelium, and an increase in the partitioning of the stomach, analogous to the development of the ruminant stomach. Investigations of this hypothesis have generally involved species with very different phylogenies or with distinctly different diets (Perrin and Curtis 1980, Korn 1992). No comparisons have been made among related species which differ only in the relative proportions of different food classes consumed.

As a logical extension of this hypothesis, it can be predicted that diet and alimentary tract morphology are reflected by life history. Specifically, species that eat high-energy foods and display digestive tract adaptations to a proteinaceous diet will possess life-history traits characteristic of relatively opportunistic species: high motility, high fecundity, and the ability to exploit temporarily ideal but relatively unstable habitats, while those with adaptations to an herbivorous diet should possess converse life history traits (Fulk 1975, Perrin and Curtis 1980).

The pampa of central Argentina is a fertile plain used for intensive agriculture. Its rodent community includes five common species (family Cricetidae) that segregate, on a gross level, according to habitat associations and life-history (de Villafañe et al. 1977, Mills et al. 1991, Mills et al. 1992a). Akodon azarae (Meyen, 1833), Bolomys obscurus (Thomas, 1916) and Oligoryzomys flavescens (Baird, 1957) are restricted to the relatively stable borders (e.g. fence lines or roadsides adjacent to crop fields); Calomys laucha (Waterhouse, 1837) and C. musculinus (Waterhouse, 1837) take advantage of highly disturbed but temporarily ideal crop habitats. C. laucha is captured almost exclusively in these habitats. C. musculinus is numerically greater in borders, but makes extensive use of crop habitats when they are favorable (Mills et al. 1992a). Calomys spp. are small-bodied, opportunistic, and highly fecund, while $B$. obscurus is larger bodied and the least fecund of the five species. A. azarae and $O$. flavescens are intermediate in body size and fecundity (Mills et al. 1991, Mills et al. 1992b). Average adult body mass ( \pm SD) for these species are (in grams): C. musculinus $-20.9( \pm 5.79, n=173)$, C. laucha -15.4 $( \pm 3.00, n=202)$, A. azarae $-20.2( \pm 4.20, n=44)$, B. obscurus $-34.0( \pm 9.24, n$ $=24)$, and $O$. flavescens $-17.1( \pm 3.40, n=29$; J. Mills, unpubl.).

Most published reports concerning the diet of these species are either anecdotal, based on very small sample sizes, or inconclusive and even contradictory. $O$. flavescens has been typically described as a seed-eater (Dalby 1975, O'Connell 1982); however, of the 10 O. flavescens stomachs examined by Barlow (1969), all 
contained plant material and half contained some invertebrate remains. We could find no published reports on the $\operatorname{diet}$ of C. musculinus. Castellarini (in litt.) found C. venustus from Córdoba province, Argentina preferred seeds and fruits, yet also ate large quantities (up to $80 \%$ of stomach contents) of foliage when the former were unavailable. Barlow (1969) described C. laucha from grassland habitats of Uruguay as predominantly herbivorous $(n=15)$. All but one of seven stomachs of B. obscurus contained primarily arthropods and A. azarae stomachs contained $70 \%$ invertebrates, $20 \%$ plant material, and $10 \%$ bait $(n=11)$. There has been no published survey comparing the diet or digestive tract morphology of these five species from a defined area and time.

We examine differences in diet and digestive tract morphology among these rodent species, and relate these observations to life history patterns. According to the extension of Vorontsov's theory (Fulk 1975, Perrin and Curtis 1980), we hypothesize that the relatively opportunistic Calomys species primarily consume high-energy food sources that are temporarily abundant in crop habitats, i.e. seeds (of crops and weeds) and insects. In contrast, the less opportunistic rodents, especially $B$. obscurus, then $A$. azarae and $O$. flavescens are expected to be relatively herbivorous, consuming the vegetation of its preferred, more stable habitat. With respect to digestive tract morphology, B. obscurus, A. azarae, and $O$. flavescens will show the following when compared to both species of Calomys: (1) a longer digestive tract in proportion to body length, (2) a higher proportion of large intestine to the length of the total digestive tract, (3) a larger and relatively more complex cecum, and (4) more compartmentalized stomachs with a smaller surface area of glandular epithelium.

\section{Methods}

Rodents were trapped from 8 November 1989 to 27 September 1990 at 17 localities in southern Santa $\mathrm{Fe}$ and northern Buenos Aires Provinces, Argentina (ca $32^{\circ} 35^{\prime}-33^{\circ} 55^{\prime} \mathrm{S}$, and $60^{\circ} 35^{\prime}-61^{\circ} 44^{\prime} \mathrm{W}$ ). In late afternoon, trap lines of 20 Sherman live traps ( 8 by 9 by $23 \mathrm{~cm}$ ) and 20 Victor snap-traps (10 by $4.5 \mathrm{~cm}$ ) were placed at 5 -m intervals in crop fields (soybeans, wheat, and corn) and in the adjacent borders of fence lines, roadsides, and railroad rights-of-way. Captured rodents were collected early the following morning and carried to a field laboratory where live-trapped animals were anesthetized, and killed by exsanguination or cervical dislocation, and all animals were necropsied. We recorded species, sex, reproductive status (testes scrotal or abdominal for males; vagina open or closed for females), and mass. Individuals of each species were divided into two mass classes (adult and subadult) based on approximate mass of sexual maturation (Mills et al. 1992b). Stomachs were fixed in $10 \%$ formalin until examined. Details concerning the study area, trapping, and processing are provided elsewhere (Mills et al. 1991).

\section{Food habits}

Stomach contents of rodents collected during the austral summer (21 December 1989-21 March 1990) were examined under a dissecting microscope $(30 x-80 x)$. The relative volumes of seeds, vegetative material (stem, foliage, or root), and insects (larval or adult) were determined for all stomachs and the percentage of stomachs containing each item was calculated for each rodent species. 
Wet mounts were made to verify classifications of food material. Significance of differences in volumes of the food items among species was assessed by Kruskal-Wallis analysis of variance by ranks (Sokal and Rohlf 1981).

\section{Digestive tract morphology}

Digestive tracts were removed in the field, extended to their full length (without stretching) on a dissecting board, and the lengths (to the nearest $\mathrm{mm}$ ) of the large intestine and small intestine were measured. Ceca were measured in horizontal and vertical dimensions and their partitions were counted.

Gross stomach morphology was determined from stomachs stored in formalin. These stomachs were bisected along a plane horizontal with the longitudinal body axis (Carleton 1973) and the

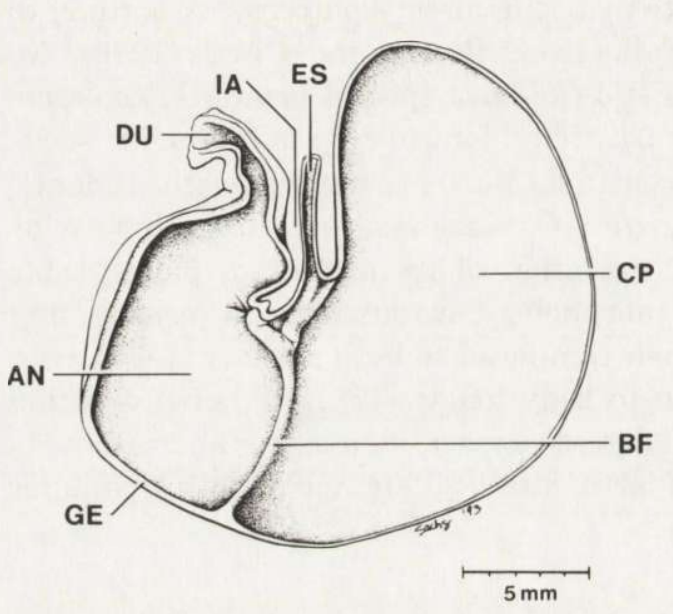

Fig. 1. Representative stomach of a Calomys musculinus captured in Santa Fe Province, Argentina. Labeled sections are: antrum (AN), corpus (CP), incisura angularis (IA), duodenum (DU), esophagous (ES), and glandular epithelium (GE). contents were washed out. To limit the variation in measurements due to the quantity of food held in the stomach at the time of capture, we chose those stomachs showing the greatest degree of distention. Measurements of the following characters were made to the nearest $0.01 \mathrm{~mm}$ using a digital caliper (terminology follows Carleton 1973; Fig. 1): maximum length and width of the antrum and corpus, length of the incisura angularis (measured from the level of the esophageal opening toward the greater curvature), and total distance between the esophageal opening and an opposite point on the greater curvature (insertion of the bordering fold). All tissue to the right of the bordering fold was taken to be glandular epithelium and that to the left squamous epithelium (Carleton 1973).

To control for differences due to the size of the animal, lengths of digestive tract components were expressed as proportions of body lengths. Differences in the measured variables were tested by 1 -way analysis of variance followed by Fisher's least significant difference multiple comparison test $(p<0.05)$. Derived proportions were transformed (arcsin square root) prior to testing. Data analyses were performed on a Macintosh II microcomputer using Excel (Microsoft Corporation 1992) and Statview II (Feldman et al. 1987).

\section{Results}

\section{Food habits}

Sample sizes of stomachs examined were $31,25,21,12$, and 9 for $C$. musculinus, C. laucha, A. azarae, $O$. flavescens, and B. obscurus, respectively. All rodent species ate each of the three classes of food items, but in varying proportions. Vegetation was present in about $55 \%$ of stomachs for all species, except for B. obscurus of which $89 \%$ ( 8 of 9 ) contained vegetation (Fig. 2). Seed consumption ranged from 




Fig. 2. Frequency (percent) of stomachs containing seed, vegetation, or insect by rodent species captured in Santa Fe Province, Argentina, from 21 December 1989 through 21 March 1990.

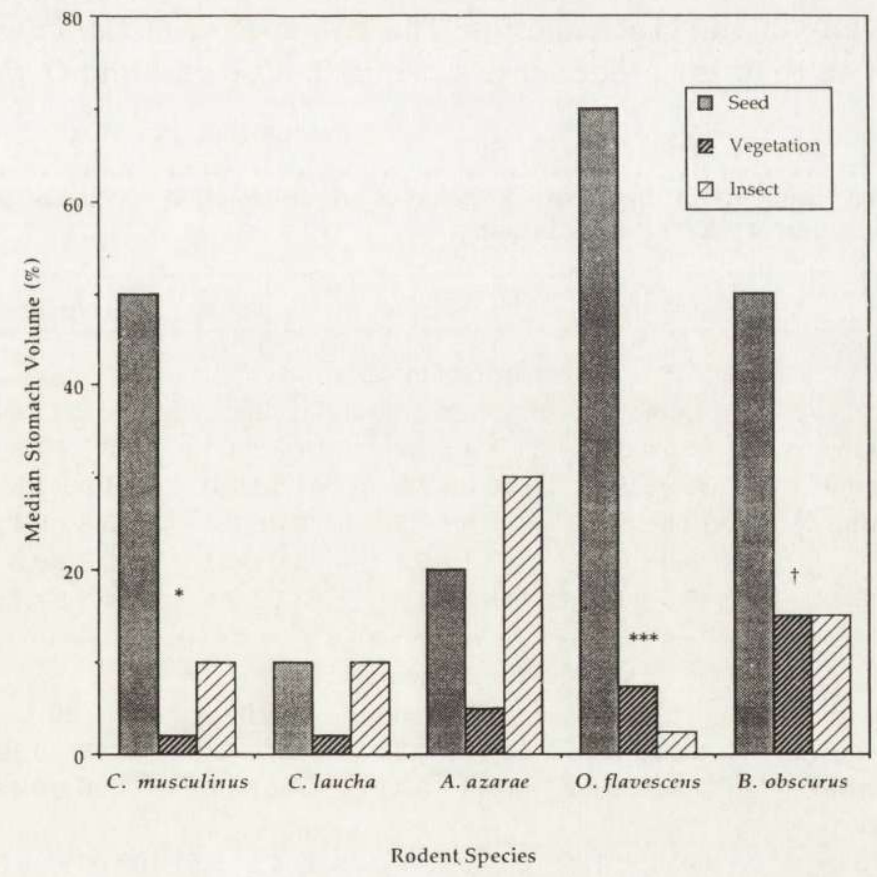

Fig. 3. Median volume of seed, vegetation, and insect in the stomachs of rodent species captured in Santa Fe Province, Argentina, from 21 December 1989 through 21 March 1990. $\dagger p=0.07, * p<0.05$, *** $p<0.001$, Kruskal-Wallis test. 
$64 \%$ ( 16 of 25 ) for C. laucha to $100 \%$ (12 of 12 ) for O. flavescens. Insect consumption ranged from $58 \%$ (18 of 31 ) for C. musculinus to $90 \%$ (19 of 21) for A. azarae.

All five species were omnivores to varying degrees, though large differences among proportions of food items consumed were observed especially for $C$. musculinus, O. flavescens, and B. obscurus (Fig. 3). O. flavescens consumed primarily seeds; all of the stomachs examined contained seeds (Fig. 2) and the overall median volume of this food item was $67 \%$ (Fig. 3). C. musculinus and B. obscurus also ate seeds (about $88 \%$ of the stomachs examined contained seeds and the average volume was $50 \%$ seeds), but consumed vegetation and insects more frequently than $O$. flavescens. An equal percentage of $B$. obscurus stomachs contained seeds and vegetation (Fig. 2), but these rodents consumed a greater volume of seeds than vegetation $(p=0.07)$. No significant differences among volumes of food items consumed were observed for C. laucha or A. azarae.

\section{Digestive tract morphology}

Measurements of body length and digestive tract components, with the associated standard errors and sample sizes are given in Table 1 . When adjusted for body size, $A$. azarae had the longest total digestive tract (small intestine, large intestine, and cecum), while the other four species did not differ significantly (Table 2). C. musculinus had the shortest small intestine, relative to body length, while $A$. azarae had the longest. $C$. musculinus had a significantly longer large intestine than any of the other species. The two species of Calomys had significantly longer ceca than the other species, while $B$. obscurus and $O$. flavescens had the shortest.

Table 1. Mean measurements of digestive tract characteristics for five species of rodents from the central Argentine pampa ( $\pm \mathrm{SE})$. Lengths in $\mathrm{mm}$.

\begin{tabular}{|c|c|c|c|c|c|}
\hline Measurement & C. musculinus & C. laucha & A. azarae & B. obscurus & O. flavescens \\
\hline \multicolumn{6}{|c|}{ Measures of intestines } \\
\hline$n$ & 42 & 45 & 27 & 21 & 25 \\
\hline Head and body length & $85.0 \pm 1.6$ & $78.4 \pm 1.2$ & $94.3 \pm 1.3$ & $112.5 \pm 1.8$ & $84.6 \pm 2.1$ \\
\hline Length small intestine & $33.0 \pm 0.9$ & $34.0 \pm 1.2$ & $51.5 \pm 2.0$ & $51.9 \pm 1.8$ & $40.3 \pm 1.4$ \\
\hline Length large intestine & $10.5 \pm 0.5$ & $8.9 \pm 0.3$ & $9.0 \pm 0.4$ & $9.8 \pm 0.4$ & $8.8 \pm 0.4$ \\
\hline Length cecum & $3.3 \pm 0.1$ & $3.1 \pm 0.1$ & $3.0 \pm 0.1$ & $2.9 \pm 0.3$ & $2.6 \pm 0.1$ \\
\hline Length total intestine & $46.5 \pm 1.2$ & $46.2 \pm 1.4$ & $63.5 \pm 2.4$ & $64.6 \pm 2.1$ & $51.8 \pm 1.7$ \\
\hline \multicolumn{6}{|c|}{ Measures of stomachs } \\
\hline$n$ & 8 & 8 & 10 & 10 & 8 \\
\hline Length of incisura angularis & $2.94 \pm 0.28$ & $0.92 \pm 0.21$ & $1.48 \pm 0.40$ & $1.43 \pm 0.19$ & $2.64 \pm 0.31$ \\
\hline $\begin{array}{l}\text { Esophageal juncture to } \\
\text { greater curvature }\end{array}$ & $7.97 \pm 0.55$ & $6.43 \pm 0.44$ & $7.42 \pm 1.02$ & $7.26 \pm 0.42$ & $9.50 \pm 0.56$ \\
\hline Length by width of antrum & $28.58 \pm 1.27$ & $54.20 \pm 6.79$ & $67.4 \pm 5.51$ & $102.06 \pm 6.52$ & $81.99 \pm 5.32$ \\
\hline Length by width of corpus & $85.36 \pm 6.83$ & $81.25 \pm 11.79$ & $109.62 \pm 10.14$ & $134.98 \pm 16.19$ & $107.07 \pm 14.02$ \\
\hline Sum of antrum + corpus & $113.94 \pm 10.031$ & $135.45 \pm 17.04$ & $177.03 \pm 13.36$ & $237.04 \pm 19.57$ & $189.06 \pm 15.70$ \\
\hline
\end{tabular}


The small intestine constituted a significantly smaller proportion of the total intestine length for C. musculinus than for any other species (Table 2). B. obscurus and $A$. azarae had the longest small intestine in relation to total intestine length, and $O$. flavescens was intermediate. The pattern of the relationships of large intestine to total intestine length was the inverse of that described for small intestine to total intestine. In relation to all other species, the two species of Calomys also had significantly longer ceca in relation to total intestine length, while $B$. obscurus had the shortest.

Stomachs were all unilocular-hemiglandular (Fig. 1). The bordering fold approximately bisected the stomach on a line from the incisura angularis to a

Table 2. Relative dimensions of portions of the digestive tract (mean $\pm \mathrm{SE}$ ) in five species of rodents from central Argentina. Lines connect means which were not significantly different $(p>0.05)$, 1-way analysis of variance on arcsin-square root transformed data, followed by Fisher's LSD multiple comparison test. TI - length of total intestine, BL - body length (without tail), SI - small intestine, LI - large intestine, CC - cecum, IA - incisura angularis, EC - distance from esophageal opening to greater curvature of stomach, AN - length $\times$ width of antrum, TT - (length $\times$ width of antrum) + (length $\times$ width of corpus), C.m. - C. musculinus, C.l. - C. laucha, B.o. - B. obscurus, O.f. - O. flavescens, A.a. - A. azarae.

\begin{tabular}{|c|c|c|c|c|c|}
\hline \multirow[b]{2}{*}{ TI/BL } & \multicolumn{2}{|c|}{$\begin{array}{c}\text { Proteinaceous } \\
\text { (High-energy diet) }\end{array}$} & \multirow{2}{*}{$\begin{array}{c}<-> \\
\text { B.o. } \\
0.597 \pm 0.021\end{array}$} & \multicolumn{2}{|c|}{$\begin{array}{c}\text { Cellulosic } \\
\text { (Low-energy diet) }\end{array}$} \\
\hline & $\begin{array}{c}\text { C.m. } \\
0.558 \pm 0.013\end{array}$ & $\begin{array}{c}\text { C.l. } \\
0.589 \pm 0.017\end{array}$ & & $\begin{array}{c}\text { O.f. } \\
0.612 \pm 0.017\end{array}$ & $\begin{array}{c}\text { A.a. } \\
0.677 \pm 0.027\end{array}$ \\
\hline SI/BL & $\begin{array}{c}\text { A.a. } \\
0.547 \pm 0.022\end{array}$ & $\begin{array}{c}\text { B.o. } \\
0.478 \pm 0.019\end{array}$ & $\begin{array}{c}\text { O.f. } \\
0.476 \pm 0.015\end{array}$ & $\begin{array}{c}\text { C.l. } \\
0.435 \pm 0.014\end{array}$ & $\begin{array}{c}\text { C.m. } \\
0.398 \pm 0.011\end{array}$ \\
\hline $\mathrm{LI} / \mathrm{BL}$ & $\begin{array}{c}\text { B.o. } \\
0.090 \pm 0.003\end{array}$ & $\begin{array}{c}\text { A.a. } \\
0.097 \pm 0.005\end{array}$ & $\begin{array}{c}\text { O.f. } \\
0.105 \pm 0.004\end{array}$ & $\begin{array}{c}\text { C.l. } \\
0.113 \pm 0.004\end{array}$ & $\begin{array}{c}\text { C.m. } \\
0.124 \pm 0.004\end{array}$ \\
\hline $\mathrm{CC} / \mathrm{BL}$ & $\begin{array}{c}\text { B.o. } \\
0.028 \pm 0.003\end{array}$ & $\begin{array}{c}\text { O.f. } \\
0.031 \pm 0.001\end{array}$ & $\begin{array}{c}\text { A.a. } \\
0.033 \pm 0.002\end{array}$ & $\begin{array}{c}\text { C.m. } \\
0.039 \pm 0.001\end{array}$ & $\begin{array}{c}\text { C.l. } \\
0.040 \pm 0.001\end{array}$ \\
\hline $\mathrm{SI} / \mathrm{TI}$ & $\begin{array}{c}\text { A. } a \text {. } \\
0.810 \pm 0.005\end{array}$ & $\begin{array}{c}\text { B.o. } \\
0.803 \pm 0.006\end{array}$ & $\begin{array}{c}\text { O.f. } \\
0.777 \pm 0.006\end{array}$ & $\begin{array}{c}\text { C.l. } \\
0.737 \pm 0.005\end{array}$ & $\begin{array}{c}\text { C.m. } \\
0.707 \pm 0.009\end{array}$ \\
\hline $\mathrm{LI} / \mathrm{TI}$ & $\begin{array}{c}\text { A. } a . \\
0.142 \pm 0.004\end{array}$ & $\begin{array}{c}\text { B.o. } \\
0.152 \pm 0.005\end{array}$ & $\begin{array}{c}\text { O.f. } \\
0.173 \pm 0.005\end{array}$ & $\begin{array}{c}\text { C.l. } \\
0.194 \pm 0.004\end{array}$ & $\begin{array}{c}\text { C.m. } \\
0.224 \pm 0.008\end{array}$ \\
\hline $\mathrm{CC} / \mathrm{TI}$ & $\begin{array}{c}\text { B.o. } \\
0.045 \pm 0.004\end{array}$ & $\begin{array}{c}\text { A. } a \text {. } \\
0.048 \pm 0.002\end{array}$ & $\begin{array}{c}\text { O.f. } \\
0.050 \pm 0.002\end{array}$ & $\begin{array}{c}C . l . \\
0.069 \pm 0.002\end{array}$ & $\begin{array}{c}\text { C.m. } \\
0.070 \pm 0.003\end{array}$ \\
\hline $\mathrm{IA} / \mathrm{EC}$ & $\begin{array}{c}\text { C.l. } \\
0.142 \pm 0.025\end{array}$ & $\begin{array}{c}\text { A. } a . \\
0.169 \pm 0.040\end{array}$ & $\begin{array}{c}\text { B.o. } \\
0.195 \pm 0.023\end{array}$ & $\begin{array}{c}\text { O.f. } \\
0.274 \pm 0.021\end{array}$ & $\begin{array}{c}\text { C.m. } \\
0.367 \pm 0.017\end{array}$ \\
\hline AN/TT & $\begin{array}{c}\text { O.f. } \\
0.449 \pm 0.370\end{array}$ & $\begin{array}{c}\text { B.o. } \\
0.443 \pm 0.026\end{array}$ & $\begin{array}{c}\text { C.l. } \\
0.411 \pm 0.030\end{array}$ & $\begin{array}{c}\text { A. } a \text {. } \\
0.386 \pm 0.022\end{array}$ & $\begin{array}{c}\text { C.m. } \\
0.236 \pm 0.046\end{array}$ \\
\hline
\end{tabular}


point opposite it on the greater curvature. The antrum and the corpus consisted of glandular epithelium and cornified squamous epithelium, respectively. The most pronounced difference among species was the relative depth of the incisura angularis. The length of the incisura, expressed as a proportion of the distance from the esophageal opening to the greater curvature, was greatest for $C$. musculinus and lowest for A. azarae and C. laucha (Table 2). The incisura for C. musculinus extended $>30 \%$ of the distance between the gastroesophageal juncture and the greater curvature. This formed a wall that partially divided the corpus from the antrum, creating a partially compartmentalized configuration. The proportion of the stomach consisting of antrum was highest for $O$. flavescens and lowest for C. musculinus, but these differences were not statistically significant (Table 2). The bordering fold was always simple and smooth. No processes such as those noted by Carleton (1981) for some microtines were observed in our specimens.

\section{Discussion}

Although all five species consistently ate significant quantities of all three classes of food items (Fig. 2), they varied in the degree to which they consumed the different food classes (Fig. 3). O. flavescens was the most granivorous, followed by $C$. musculinus and $B$. obscurus which consumed increasing amounts of vegetation and insects; $C$. laucha and $A$. azarae consumed fairly equal proportions of seeds and insects. None of the species could be classified as strict herbivores, but $B$. obscurus more frequently consumed vegetative plant material than any of the other species (Fig. 2).

The species can be ranked along a scale from proteinaceous to cellulosic diets, as defined by Vorontzov (1962), by calculating the median proportion of stomach volume consisting of seeds and insects. Although the range is narrow (80-96\%), C. laucha and A. azarae (96 and 95\%, respectively) are at the proteinaceous end, followed by $C$. musculinus $(90 \%)$ and $O$. flavescens $(88 \%)$. Bolomys obscurus $(80 \%)$ had the most cellulosic diet of the five species. Thus, while considerable overlap was observed in the diet of the five species, the smallest, most opportunistic species (C. laucha) consumed more high-energy foods, while the largest, and most restricted to the stable border habitats ( $B$. obscurus) had the most cellulosic diet.

The digestive tracts of these rodents, when characterized as adapted for cellulosic or proteinaceous diets, are generally converse to what is expected, given diet (Table 2). The digestive tract of $C$. musculinus and $C$. laucha most closely match predictions for a cellulosic diet, while that of $B$. obscurus would indicate a relatively proteinaceous diet.

Other studies have found more concordance between digestive tract morphology and diet. Perrin and Curtis (1980) found the relative lengths of portions of the gut for 19 South African rodents to conform to predictions of the Vorontsov's hypothesis. The mean percentages for length of the intestine accounted for by 
small intestine, large intestine, and cecum, respectively, for 12 omnivorous rodents were 63.1 (range: 50.9-80.1), $29.0(16.2-46.5)$, and 7.9 (0.0-11.4). For two herbivores, the proportions were 42.0 and $42.2,37.8$ and 39.4, and 20.2 and 18.4, respectively. According to Davis and Golley (1963), the mean percentage of length of the digestive tract accounted for by the small intestine, large intestine, and cecum, respectively, for 10 herbivorous rodents was: 54.3 (range: 23-73), 30.0 (range: 20-47), and 16.5 (range 6-52). For four omnivorous rodents these figures were: 81.0 (range: 78-84), 16.0 (range: $13-18$ ), and 3.25 (range 3-4).

Proportions of the digestive tracts which were small intestine, large intestine, and cecum, respectively, for C. musculinus $(70.7,22.4$, and 7.0) and C. laucha (73.7, 19.4, and 6.9) are within or very close to the range identified by Davis and Golley (1963) for herbivorous rodents, yet neither species ate appreciable quantities of vegetation. A. azarae (81.0, 14.2, and 4.8), B. obscurus (80.3, 15.2, and 4.5), and $O$. flavescens $(77.7,17.3$, and 5.0 ) have digestive tracts that are close to the proportions identified for omnivorous rodents (Davis and Golley 1963). However, all five pampa rodents fall easily into the large range identified by Perrin and Curtis (1980) for omnivores.

Korn (1992) found differences in relative length of the intestine with sex and reproductive status. We found no significant differences in the relative lengths of the total intestine, small or large intestine, or cecum between sexes, or between reproductively mature and immature individuals, or between mass classes for any of the five species in this study (Mann-Whitney $U$-test; $p>0.05$ ).

While there was some concordance between diet and life history patterns, digestive tract structure was not consistent with what was hypothesized (Vorontsov 1962, Fulk 1975, Perrin and Curtis 1980). One explanation, in the case of Calomys spp. is that these species evolved in a relatively stable, pre-agricultural grassland environment, and have only recently moved into the unstable crop habitats created by humans. Furthermore, availability of seeds and insects on the pampa is seasonal. Plasticity of gut morphology in response to short-term changes in food quality and energy needs has been documented (Gross et al. 1985, Weiner 1992). To minimize such changes in gut morphology, and to have the greatest chance of detecting differences, we restricted our comparisons to a three-month period during the summer, when all major categories of food items are available. Finally, measurement of volume of the large intestine and ceca, as well as actual surface area in the small intestine (e.g. measurements of folds, villi, and microvilli), would be necessary to substantiate that differences in lengths of intestine reflect functional differences.

On the other hand, the Vorontsov's hypothesis or its extension involving life-history traits, may be flawed. The original hypothesis is based on an analogy with the digestive system of ruminants. While symbiotic bacilli have been described in Mystromys albicaudatus (Maddock and Perrin 1981, 1983, Perrin and Kokkinn 1986), the presence of cellulolytic gastric symbionts has yet to be documented for most herbivorous rodents (Carleton 1973). The extension of the 
hypothesis is based on the assumption that species that are opportunistic in habitat selection use more high-energy foods than those that are restricted to more stable habitats (Fulk 1975, Perrin and Curtis 1980). This may not be accurate, at least in the case of pampa rodents. Despite distinct differences in habitat associations and life-history patterns, all five pampa rodent species might be described as omnivores to varying degrees. All appear to exploit relatively high-energy seeds and invertebrates, at least seasonally, and none are strict herbivores. The degree to which alimentary tracts vary within these species may reflect the spectrum of variation encountered within an omnivore rodent guild, rather than the degree of food specialization within the community.

Acknowledgments: Drs C. J. Peters, J. W. LeDuc, and K. T. McKee, Jr, provided active support throughout this study. Dr G. Gurri Glass provided valuable comments on the manuscript. We thank H. Lopez, A. Fernandez, and D. Olivera for help in the field and M. Muzzini with assistance in the diet analysis. This research was funded by a subcontract to Johns Hopkins University from the Pan American Health Organization on grant 17-87-C-7013 from the United States Army Medical Research and Development Command. The first author was partially supported by awards from Achievement Rewards for College Scientists Foundation (Metropolitan Washington Chapter) and by the American Association of University Women.

\section{References}

Barlow J. C. 1969. Observations on the biology of rodents in Uruguay. Life Sciences Contributions, Royal Ontario Museum, Toronto 75: 1-59.

Carleton M. D. 1973. A survey of gross stomach morphology in new world Cricetinae (Rodentia, Muroidea), with comments on functional interpretations. Miscellaneous Publications, The Museum of Zoology, University of Michigan 146: 1-43.

Carleton M. D. 1981. A survey of gross stomach morphology in Microtinae (Rodentia: Muroidea). Z. Säugetierk. 46: 93-108.

Dalby P. L. 1975. Biology of Pampa rodents. Publications of the Museum, Michigan State University, Biological Series 5: 149-272.

Davis D. E. and Golley F. B. 1963. Principles in mammalogy. Reinhold Publishing Corporation, New York: $1-335$

Feldman D. S. Jr, Gagnon J., Hofmann R., and Simpson J. 1987. Statview II Manual. Version 1.03. Abacus Concepts, Inc., Berkeley, CA. [on disk]

Fulk G. W. 1975. Population ecology of rodents in the semiarid shrublands of Chile. Occasional Papers, The Museum, Texas Tech University 33: 1-40.

Gross J. E., Wang Z., and Wunder B. A. 1985. Effects of food quality and energy needs: changes in gut morphology and capacity of Microtus ochrogaster. J. Mammal. 66: 661-665.

Korn H. 1992. Intestine lengths of southern African savanna rodents and insectivores: intra- and interspecific comparison. J. Zool., Lond. 228: 455-460.

Maddock A. H. and M. R. Perrin. 1981. A microscopical examination of the gastric morphology of the white-tailed rat Mystromys albicaudatus (Smith, 1834). S. Afr. J. Zool. 16: 237-247.

Maddock A. H. and M. R. Perrin. 1983. Development of the gastric morphology and fornical bacterial/epithelial association in the white-tailed rat Mystromys albicaudatus (Smith, 1834). S. Afr. J. Zool. 18: 115-127.

Microsoft Corporation. 1992. Microsoft Excel User's Guide. Version 2.2. Microsoft Corporation, Redmond, Washington. [on disk] 
Mills J. N., Ellis B. A., McKee K. T., Calderon G. E., Maiztegui J. I., Nelson G. O., Ksiazek T. G., Peters C. J., and Childs J. E. 1992a. A longitudinal study of Junin virus activity in the rodent reservoir of Argentine hemorrhagic fever. Am. J. Trop. Med. Hyg. 47: 749-763.

Mills, J. N., Ellis B. A., McKee K. T., Maiztegui J. I., and Childs J. E. 1991. Habitat associations and relative densities of rodent populations in cultivated areas of central Argentina. J. Mammal. 72: $470-479$

Mills J. N., Ellis B. A., McKee K. T. Jr, Maiztegui J. I., and Childs J. E. 1992b. Reproductive characteristics of the rodent community in cultivated areas of central Argentina. J. Mammal. 73: $515-526$.

O'Connell M. A. 1982. Population biology of North and South American grassland rodents: a comparative review. [In: Mammalian biology in South America. M. A. Mares and H. H. Genoways, eds]. Special Publications Series, Pymatuning Laboratory of Ecology, University of Pittsburgh, Linesville, PA: 167-185.

Perrin M. R. and Curtis B. A. 1980. Comparative morphology of the digestive system of 19 species of southern African myomorph rodents in relation to diet and evolution. S. Afr. J. Zool. 15: 22-23.

Perrin M. R. and Kokkinn M. J. 1986. Comparative gastric anatomy of Cicetomys gambianus and Saccostomus campestris (Cricetomyinae) in relation to Mystromys albicaudatus (Cricetinae). S. Afr. J. Zool. 21: 202-210.

Sokal R. R. and Rohlf F. J. 1981. Biometry. W. H. Freeman Co., San Francisco: 1-776.

Villafañe G., de, Kravetz F. O., Donadio O., Percich R., Knecher L., Torres M. P., and Fernandez N. 1977. Dinámica de las comunidades de roedores en agroecosistemas pampásicos. Medicina (Buenos Aires) 37: 128-140.

Vorontsov N. N. 1962. The ways of food specialization and evolution of the alimentary system in Muroidea. [In: Symp. Theriol. Proc. Inter. Symp. Methods of Mammalogical Investigation. J. Kratochvil and J. Pelikan, eds]. Publ. House of the Czechoslovak Academy of Sciences, Praha: 360-377.

Weiner J. 1992. Physiological limits to sustainable energy budgets in birds and mammals: ecological implications. Trends in Ecology and Evolution 7: 384-388.

Received 3 February 1994, accepted 4 August 1994 